\title{
The Isolation of Pregnane-3( $\alpha$-ol-20-one from the Hydrolysis Products of 'Sodium Pregnanediol Glucuronidate'
}

\author{
By G. F. MARRIAN AND NANCY GOUGH, Department of Biochemistry, University of Edinburgh
}

\author{
(Received 14 February 1946)
}

In 1941 Astwood \& Jones described a convenient method for the determination of pregnanediol in human urine involving the following steps: (i) hydrolysis of the urine with $\mathrm{HCl}$; (ii) extraction with toluene; (iii) removal of acidic material from the toluene extract; (iv) elimination of substances other than pregnanediol from the neutral toluenesoluble fraction by precipitations from ethanolic solution with dilute $\mathrm{NaOH}$ and with water; and (v) weighing of the purified pregnanediol obtained. Talbot, Berman, MacLachlan \& Wolfe (1941) employed somewhat similar methods for extracting the urine and for working up the product, but determined the pregnanediol colorimetrically by means of the reaction with concentrated $\mathrm{H}_{2} \mathrm{SO}_{4}$, instead of weighing it. In experiments in which supposedly pure sodium pregnanediol glucuronidate was added in known amounts to human male urine both groups of workers reported recoveries of only about $70 \%$ of theoretical.

In the course of an investigation designed to develop a simple method for determining pregnanediol in the urine of non-pregnant women the present authors have carried out experiments in which supposedly pure sodium pregnanediol glucuronidate was hydrolyzed in pure aqueous solution by the method of Astwood \& Jones and the liberated pregnanediol estimated colorimetrically by means of the $\mathrm{H}_{2} \mathrm{SO}_{4}$ reaction after extraction with toluene. Even by such a simplified procedure in which the experimental losses might have been expected to be minimal, not more than about $70 \%$ of the theoretical amount of pregnanediol could be recovered.

It seemed possible that the low yield of preg. nanediol obtainable from the glucuronide might be the result of some side reaction occurring simultaneously with the hydrolysis of the glucuronide linkage. By analogy with the formation of androstene-17-one from androsterone sulphate by acid hydrolysis (Venning, Hoffman \& Browne, 1942) it was thought that the acid hydrolysis of pregnanediol glucuronide might conceivably lead to the formation of a small proportion of $\Delta^{2}$ or ${ }^{3}$-pregnene20-ol. In order to investigate such a possibility it was decided to hydrolyze a considerable quantity of sodium pregnanediol glucuronidate and conduct a careful fractionation of the product.

\section{RESULTS}

Purified sodium pregnanediol glucuronidate was hydrolyzed with $\mathrm{HCl}$ in the presence of toluene under conditions approximating to those used by Astwood \& Jones (1941). By repeated leaching with hexane the toluene-soluble material obtained from the hydrolysis was separated into two fractions differing sharply from one another in appearance and solubilities. The fraction less soluble in hexane, which amounted to $80 \%$ of the total hydrolysis product obtained, appeared to be nearly pure pregnanediol. The fraction more soluble in hexane was adsorbed on a column of $\mathrm{Al}_{2} \mathrm{O}_{3}$ in benzene-hexane and fractionally eluted first with benzene-hexane and then with benzene. From the benzene eluates a crystalline product was obtained which after recrystallization melted at $149-150^{\circ}$ and had $[\alpha]_{D}=+109^{\circ}$. This substance gave analytical figures closely agreeing with those required for a compound of the formula $\mathrm{C}_{21} \mathrm{H}_{34} \mathrm{O}_{2}$; it gave no precipitate with digitonin in $90 \%(\mathrm{v} / \mathrm{v})$ aqueous ethanol and in the Zimmermann test, using the technique of Callow, Callow \& Emmens (1938), it gave a brick red tint like that given by 20 -ketosteroids but quite unlike the pink colour given by 17 -ketosteroids. It yielded an acetate melting at $98-99^{\circ}$ and a semicarbazone melting at $246-249^{\circ}$.

The properties of the substance and of its derivatives'suggested that it was pregnane-3( $\alpha)$-ol20-one which was first isolated from human pregnancy urine by Marker \& Kamm (1937). Mixed melting-points of the compound, its acetate and its semicarbazone with authentic pregnane$3(\alpha)$-ol-20-one and the acetate and semicarbazone of the latter respectively showed that this was indeed so.

Since it seemed extremely unlikely that this pregnanolone could be formed from pregñanediol glucuronide during hydrolysis with $\mathrm{HCl}$, the possibility was entertained that the original sodium pregnanediol glucuronidate might have contained a water-soluble derivative of pregnane-3( $\alpha)$-ol-20-one as an impurity. To test this hypothesis six different preparations of sodium pregnanediol glucuronidate, each of which had been carefully 'purified', were tested in 4-5 mg. quantities with the Zimmermann 
reagents; each sample gave the brick-red colour characteristic of 20 -ketosteroids.

Since the foregoing experiments suggested that sodium pregnanediol glucuronidate prepared and purified in the usual manner contains a watersoluble derivative of pregnane-3( $\alpha)$-ol-20-one as an impurity, an experiment was next carried out in order to see whether this pregnanolone derivative could be removed by more rigorous purification. A 'purified' sample of sodium pregnanediol glucuronidate was subjected to two further crystallizations from $90 \%(v / v)$ aqueous ethanol and two precipitations from $50 \%(\mathrm{v} / \mathrm{v})$ aqueous acetone solution by acetone. After each purification procedure the product was tested qualitatively* by the Zimmermann reaction and the pregnanediol content determined colorimetrically after acid hydrolysis. This further purification resulted in no visible diminution in intensity of the Zimmermann reaction and no significant alteration in the pregnanediol content. The melting-point also remained unchanged through this further 'purification'.

The main bulk of this further 'purified' sodium pregnanediol glucuronidate was hydrolyzed with $\mathrm{HCl}$ and the toluene-soluble material isolated. A roughly quantitative Zimmermann reaction showed the crude hydrolysis product to contain about $23 \%$ of 20-ketosteroid. A separation in the usual manner with trimethylammoniumacetohydrazide chloride (Girard's reagent T) yielded a ketonic fraction amounting to about $17 \%$ of the total. Pregnane$3(\alpha)$-ol-20-one was isolated from this fraction after adsorption on a column of $\mathrm{Al}_{2} \mathrm{O}_{3}$ and crystallization from hexane.

The findings reported here clearly show that 'sodium pregnanediol glucuronidate' as prepared by the present authors contains about $20 \%$ of a water-soluble derivative of pregnane-3( $\alpha)$-ol-20one-presumably the sodium salt of the glucuronide, which cannot be removed by acetone precipitation or by crystallization from $90 \%(\mathrm{v} / \mathrm{v})$ aqueous ethanol. It is reasonable to assume therefore that sodium pregnanediol glucuronidate prepared by others may be similarly contaminated.

In the course of this work it has been found that not only is pregnane-3( $\alpha)$-ol-20-one only feebly chromogenic in the $\mathrm{H}_{2} \mathrm{SO}_{4}$ reaction, but that in the quantities likely to be present it is completely eliminated by the ethanol-water precipitation process used by Astwood \& Jones (1941) in the determination of pregnanediol. If the present authors are correct in their belief that sodium pregnanediol glucuronidate has not so far been obtained from pregnancy urine free from pregnane-3( $\alpha)$-ol-

* Owing to the relative insolubility of 'sodium pregnanediol glucuronidate' in absolute ethanol, quantitative determinations of the ketosteroid content by the photoelectric absorptiometer were not possible. 20-one, the low yields of pregnanediol obtained by Astwood \& Jones (1941), by Talbot et al. (1941) and by themselves from the glucuronidate after acid hydrolysis may be partly accounted for.

A point of no little importance in connexion with the determination of pregnanediol in urine as sodium pregnanediol glucuronidate by the original method of Venning $(1937,1938)$ has emerged from the present work. Venning (1937) stated that sodium pregnanediol glucuronidate contains $1 \mathrm{~mol}$. of water of crystallization, and a factor for the conversion of weight of glucuronidate to weight of pregnanediol was worked out on this basis. Recently Bloch (1945) has shown that sodium pregnanediol glucuronidate crystallized from $90 \%$ aqueous ethanol loses about $6.5 \%$ of its weight on drying in vacuo at $137^{\circ}$, a weight loss corresponding to the loss of $2 \mathrm{~mol}$. of water of crystallization. Carbon and hydrogen analyses showed that undoubtedly the dried material was anhydrous sodium pregnanediol glucuronidate. Bloch furthermore has shown that the anhydrous glucuronidate takes up 2 mol. of water on exposure to air. In the present work it has been found that 'sodium pregnanediol glucuronidate' previously dried at room temperature in vacuo over $\mathrm{CaCl}_{2}$ loses about $9.4 \%$ of its weight on drying in vacuo over $\mathrm{P}_{2} \mathrm{O}_{5}$ at $137^{\circ}$ for $10 \mathrm{hr}$. This loss of weight corresponds to the loss of $3 \mathrm{~mol}$. of water. On exposure to the air the dried material, the carbon hydrogen and sodium contents of which agreed closely with those required for the anhydrous glucuronidate, rapidly took up $3 \mathrm{~mol}$. of water. The uptake of water was nearly complete after $3 \mathrm{hr}$. The discrepancy between these findings and those of Bloch might be accounted for by the difference in relative humidity between an Edinburgh and a New York laboratory. Whether this is the case or not it is clear that no worker should use a sodium pregnanediol glucuronidate-pregnanediol conversion factor which has not been worked out by himself under rigidly controlled conditions.

\section{EXPERIMENTAL}

\section{Preparation of 'sodium pregnanediol glucuronidate'}

Late pregnancy urine, preserved with toluene or butanol, was extracted two or three times with butanol as soon as possible after collection. The butanolic extracts were washed several times with $\mathrm{N}$ - or $\mathrm{N} / 3-\mathrm{NaOH}$, and water, and evaporated under reduced pressure to dryness. The residue was dissolved in $\mathrm{N}$ - or $\mathrm{N} / 3-\mathrm{NaOH}$, and extracted several times with butanol. After washing several times with water, the butanolic extract was evaporated, to dryness. The material obtained in this way was dispersed with warming in $50 \%(\mathrm{v} / \mathrm{v})$ aqueous acetone and the solution filtered hot. Crude sodium pregnanediol glucuronidate was precipitated from the filtrate by the addition of $10 \mathrm{vol}$. of dry acetone. After standing overnight the precipitate was 
filtered by suction and washed with dry acetone. Purification was effected by one or two reprecipitations from $\mathbf{5 0 \%}$ $(v / v)$ aqueous acetone with dry acetone and by one or two crystallizations from $50 \%(v / v)$ aqueous acetone or $90 \%$ $(\mathrm{v} / \mathrm{v})$ aqueous ethanol.

\section{Pregnane-3( $\alpha)$-ol-20-one from the hydrolysis products of 'sodium pregnanediol glucuronidate'}

$0.80 \mathrm{~g}$. of the glucuronidate, m.p. $280^{\circ}$ (decomp. and evolution of gas) (corr.), was refluxed with $2000 \mathrm{ml}$. of water until dissolved. Toluene $(500 \mathrm{ml}$.) and conc. $\mathrm{HCl}$ (A.R. $200 \mathrm{ml}$.) were then added and boiling continued for $15 \mathrm{~min}$. After cooling the toluene layer was separated off and the aqueous phase re-extracted twice with $500 \mathrm{ml}$. lots of toluene. After washing once with $200 \mathrm{ml} .5 \% \mathrm{NaHCO}_{3}$ and twice with $200 \mathrm{ml}$. lots of water the combined toluene extracts were evaporated to dryness, yielding $0.46 \mathrm{~g}$. of a white solid.

The product was refluxed for $15 \mathrm{~min}$. with $30 \mathrm{ml}$. of $n$-hexane, and after cooling overnight at $0^{\circ}$, the mixture was filtered. The material insoluble in cold hexane was leached three times more in the same manner with hexane. Judging by the decrease in weight of the less soluble fraction, three leachings were sufficient to remove all of the material more soluble in hexane. Evaporation of the combined hexane filtrates yielded $0 \cdot 10 \mathrm{~g}$. of a colourless gum which crystallized on standing. The hexane-insoluble fraction melted sharply at $234-235^{\circ}$ (corr.) and was evidently nearly pure pregnanediol.

The hexane-soluble fraction was dissolved in a mixture of equal volumes of benzene and hexane and passed through a column of $\mathrm{Al}_{2} \mathrm{O}_{3}$ (Merck's 'nach Brockmann') $11 \times 1 \mathrm{~cm}$. The column was then eluted successively with three $20 \mathrm{ml}$. lots of benzene-hexane and fourteen $20 \mathrm{ml}$. lots of benzene. Evaporation of the benzene-hexane and the first three benzene eluates yielded only traces of gum. The remaining benzene eluates, however, yielded $30 \mathrm{mg}$. of a white crystalline solid material melting at $145-149^{\circ}$ (corr.). After two crystallizations from $n$-hexane beautiful rosettes of needles melting at $149-150^{\circ}$ (corr.) were obtained. This crystalline material contained solvent of crystallization which was only completely removed after prolonged drying at $80^{\circ}$ in vacuo.

The substance was not precipitated by digitonin from $90 \%(v / v)$ aqueous ethanolic solution, and in the Zimmermann test a brick-red colour was shown. Found: C, $79.4 ; \mathrm{H}, 10.8 \%$; Calc. for $\mathrm{C}_{21} \mathrm{H}_{34} \mathrm{O}_{2}: \mathrm{C}, 79 \cdot 2 ; \mathrm{H}, 10 \cdot 8 \%$. $[\alpha]_{D}^{13^{\circ}}=+109^{\circ}$; $(4.933 \mathrm{mg}$. in $0.5 \mathrm{ml}$. absolute ethanol). Mixed with authentic pregnane-3( $\alpha)$-ol-20-one (prepared from pregnanedione by a slight modification of the method of Marker, Kamm \& Wittle (1937); m.p. 147-149.5 ${ }^{\circ}$ corr.; $[\alpha]_{D}^{13^{\circ}}=+107^{\circ}$ ), the melting-point was $147-149 \cdot 5^{\circ}$ (corr.).

Acetylation by heating at $100^{\circ}$ for $1.5 \mathrm{hr}$. with acetic anhydride yielded a product which, after two crystallizations from aqueous ethanol, melted at 98-99 ${ }^{\circ}$ (corr.). Found: C, 76.5; H, 10.0\%; Calc. for $\mathrm{C}_{23} \mathrm{H}_{36} \mathrm{O}_{3}: \mathrm{C}, 76 \cdot 6 ; \mathrm{H}$, $10 \cdot 1 \%$. Mixed with authentic pregnane-3( $\alpha)$-ol-20-one acetate (m.p. 98-100.5 $5^{\circ}$ corr.) the melting-point was 98$100.5^{\circ}$ (corr.).

By treatment with semicarbazide hydrochloride and sodium acetate for 3 days at room temperature in aqueous ethanolic solution, a product was obtained which after one crystallization from absolute ethanol and one from 50\% (v/v) aqueous ethanol melted at $246-249^{\circ}$ (corr.; slight decomp.). Found: $\mathrm{N}, 11 \cdot 0 \%$. Calc. for $\mathrm{C}_{22} \mathrm{H}_{37} \mathrm{O}_{2} \mathrm{~N}_{3}: \mathrm{N}$, $11 \cdot 2 \%$. Mixed with authentic pregnane-3( $\alpha)$-ol-20-one semicarbazone (m.p. $248-251^{\circ}$; slight decomp.), the meltingpoint was $248-251^{\circ}$ (corr.).

\section{Persistence of ketosteroid in 'sodium pregnanediol glucuronidate' after further purification}

The material used in this experiment was obtained by combining several different batches, each of which had been prepared and purified by the methods described. In order that the starting material should be homogeneous it was dissolved in the minimum volume of hot $50 \%(\mathrm{v} / \mathrm{v})$ aqueous acetone and precipitated with $10 \mathrm{vol}$. of dry acetone. The precipitated glucuronidate was filtered with suction, washed with dry acetone and dried at room temperature in vacuo over $\mathrm{CaCl}_{2}$. The melting-point of this material (A) was $282-283^{\circ}$ (corr.). A small sample was set aside for preliminary analysis.

$3.011 \mathrm{mg}$. A dried for $10 \mathrm{hr}$. in vacuo over $\mathrm{P}_{2} \mathrm{O}_{5}$ at $137^{\circ}$ lost

After exposure to air for $22 \mathrm{hr}$. the dried material gained

On redrying as above the sample lost

After re-exposure to air for $22 \mathrm{hr}$. the sample gained

Average weight lost and gained by sample=

mg.

$0 \cdot 248$

$0 \cdot 285$

$0 \cdot 309$

$0 \cdot 285$

$0.282 \mathrm{mg}$. is $9.4 \%$ of the original weight of the sample. Calc. for $\mathrm{C}_{27} \mathrm{H}_{43} \mathrm{O}_{8} \mathrm{Na} .3 \mathrm{H}_{2} \mathrm{O} ; 9 \cdot 4 \% \mathrm{H}_{2} \mathrm{O}$.

$2 \cdot 164 \mathrm{mg}$. dried for $10 \mathrm{hr}$. in vacuo over $\mathrm{P}_{2} \mathrm{O}_{5}$ gave $4.991 \mathrm{mg}$. $\mathrm{CO}_{2}, 1.581 \mathrm{mg} . \mathrm{H}_{2} \mathrm{O}$, and a residue which after treatment with concentrated $\mathrm{H}_{2} \mathrm{SO}_{4}$ gave $0.301 \mathrm{mg}$. $\mathrm{Na}_{2} \mathrm{SO}_{4}$. Found: C, 62.8; $\mathrm{H}, 8.2 ; \mathrm{Na}, 4.5 \%$; Calc. for $\mathrm{C}_{27} \mathrm{H}_{43} \mathrm{O}_{8} \mathrm{Na}$ : C, 62.5; H, 8.4; Na, $4 \cdot 4 \%$.

The pregnanediol content after hydrolysis was determined in the following way: $5.067 \mathrm{mg}$. of A (undried) were dissolved in $10 \mathrm{ml}$. of $50 \%(\mathrm{v} / \mathrm{v})$ aqueous ethanol. $1.0 \mathrm{ml}$. of this solution was added to $500 \mathrm{ml}$. of water and $100 \mathrm{ml}$. toluene and the mixture heated to boiling under a reflux condenser. To the boiling mixture $50 \mathrm{ml}$. of conc. $\mathrm{HCl}$ (A.R.) were added and boiling was continued for $10 \mathrm{~min}$. After rapid cooling the mixture was transferred to a separating funnel, shaken thoroughly and the toluene layer separated off. The aqueous phase was reextracted twice more with $100 \mathrm{ml}$. lots of toluene. The combined toluene extracts were washed twice with $100 \mathrm{ml}$. lots of $\mathrm{N}-\mathrm{NaOH}$, twice with $100 \mathrm{ml}$. lots of water, and evaporated to dryness under reduced pressure. The residue was quantitatively transferred to a 1 in. test-tube with ethanol and after evaporation of the solution $10 \mathrm{ml}$. of conc. $\mathrm{H}_{2} \mathrm{SO}_{4}$ (A.R.) were added. The tube was stood in a water-bath at $25^{\circ}$ for $20 \mathrm{~min}$. with occasional shaking, and the yellow colour which developed was measured in a 'Spekker' absorptiometer using a 'spectrum violet' filter. The pregnanediol equivalents read from a previously constructed calibration curve, were in triplicate experiments found to be $0 \cdot 195,0 \cdot 190$ and $0 \cdot 192 \mathrm{mg}$. The average of these corresponds to a pregnanediol content of $68 \%$ of that theoretically required if the starting material had been pure sodium pregnanediol glucuronidate, $3 \mathrm{H}_{2} \mathrm{O}$. A Zimmermann test carried out on $5 \cdot 2 \mathrm{mg}$. of $\mathrm{A}$ by the Callow procedure was strongly positive. 
$1.79 \mathrm{~g}$. of A was dissolved in $200 \mathrm{ml}$. of boiling $90 \%$ (v/v) aqueous ethanol. After standing overnight at $0^{\circ}$, the crystalline material which had separated was filtered with suction, washed with cold $90 \%(\mathrm{v} / \mathrm{v})$ aqueous ethanol, and dried at room temperature in vacuo over $\mathrm{CaCl}_{2}$. A yield of $1 \cdot 11 \mathrm{~g}$. of material (B) melting at $282^{\circ}$ (corr.) was obtained.

The pregnanediol content of $B$ after hydrolysis determined in duplicate as described above was found to be $70 \%$ of theoretical. A Zimmermann test on $4.5 \mathrm{mg}$. B was strongly positive.

$1.09 \mathrm{~g}$. of $\mathrm{B}$ was recrystallized as described above from $130 \mathrm{ml}$. of $90 \%(\mathrm{v} / \mathrm{v})$ aqueous ethanol. A yield of $0.719 \mathrm{~g}$. of material (C) melting at $282^{\circ}$ (corr.) was obtained. The pregnanediol content of $\mathrm{C}$ after hydrolysis was found to be $66 \%$ of theoretical. A Zimmermann test on $5.0 \mathrm{mg}$. was strongly positive.

$0.706 \mathrm{~g}$. of $\mathrm{C}$ was dissolved in $35 \mathrm{ml}$. hot $50 \%(\mathrm{v} / \mathrm{v})$ aqueous acetone. Precipitation was effected by the addition of $350 \mathrm{ml}$. of dry acetone. After standing for $5 \mathrm{hr}$. the precipitate was filtered with suction, washed with dry acetone, and dried at room temperature in vacuo over $\mathrm{CaCl}_{2}$. A yield of $0 \cdot 674 \mathrm{~g}$. of material (D) melting at 282$283^{\circ}$ (corr.) was obtained. The pregnanediol content of $D$ after hydrolysis was found to be $60 \%$ of theoretical. A Zimmermann test on $4 \cdot 1 \mathrm{mg}$. was strongly positive.

$0.663 \mathrm{~g}$. of $\mathrm{D}$ was reprecipitated from $50 \%(\mathrm{v} / \mathrm{v})$ aqueous acetone exactly as described above. $0 \cdot 644 \mathrm{~g}$. of material (E) melting at $282^{\circ}$ (corr.) was obtained. The pregnanediol content of $\mathrm{E}$ after hydrolysis was found to be $69^{\prime} \%$ of theoretical. A Zimmermann test on $5.0 \mathrm{mg}$. was strongly positive.

Pregnane-3( $\alpha)$-ol-20-one from the hydrolysis products of further 'purified' 'sodium pregnanediol glucuronidate,

$0.632 \mathrm{~g}$. of preparation $\mathrm{E}$ (see above) was hydrolyzed and extracted as previously described. The total toluene-soluble hydrolysis product weighed $0 \cdot 348 \mathrm{~g}$. and melted at 224 $228^{\circ}$ (corr.) with preliminary sintering at $216^{\circ}$.

Duplicate determinations of the 20-ketosteroid content were carried out on $1.11 \mathrm{mg}$. amounts by the Callow technique, but using a 'spectrum blue-green' instead of a 'spectrum green' filter. The absorptiometer readings were referred to a pregnane-3( $\alpha)$-ol-20-one calibration curve. The average of the two determinations gave a 20-ketosteroid content of $23 \%$.

The hydrolysis product was dissolved in a mixture of $20 \mathrm{ml}$. ethanol and $1.5 \mathrm{ml}$. of glacial acetic acid. Trimethylammonium acetohydrazide chloride $(360 \mathrm{mg}$.) was added and the mixture heated under reflux for $60 \mathrm{~min}$. on a boiling water-bath and then cooled. A solution of $940 \mathrm{mg}$. $\mathrm{NaOH}$ (sufficient to neutralize $9 / 10$ of the acetic acid) in $160 \mathrm{ml}$. ice-cold water was then added, and after standing at $0^{\circ}$ for $2 \mathrm{hr}$. the mixture was extracted three times with $100 \mathrm{ml}$. portions of ether. The combined ether extracts were washed once with water and evaporated to dryness. The non-ketonic fraction obtained thus weighed $0.28 \mathrm{~g}$. and melted at $228-230^{\circ}$ (corr.) after preliminary softening at $216^{\circ}$. A Zimmermann test on $5 \mathrm{mg}$. was completely negative.

The aqueous phase together with the water-washing of the ether extract was acidified with $16 \mathrm{ml}$. conc. $\mathrm{HCl}$ and allowed to stand for 2 days at room temperature. The mixture was extracted three times with $100 \mathrm{ml}$. portions of ether and the combined ether extracts evaporated to dryness. The residue was repeatedly leached with liberal amounts of boiling hexane, and the combined hexane leachings evaporated to dryness. A yield of $0.0596 \mathrm{~g}$. of hot hexane-soluble ketonic material, corresponding to $17 \%$ of the total toluene-soluble hydrolysis product, was obtained.

This material was adsorbed on a column of $\mathrm{Al}_{2} \mathrm{O}_{3}$ in benzene-hexane and eluted with pure benzene. The benzene eluates were combined and evaporated to dryness. The residue after crystallization from $n$-hexane yielded $31 \mathrm{mg}$. of white needles, melting at $148-149 \cdot 5^{\circ}$ (corr.). On mixing with authentic pregnane-3( $\alpha)$-ol-20-one the melting-point was unchanged.

Acetylation with acetic anhydride gave a product which after two crystallizations from $50 \%(v / v)$ aqueous ethanol melted at $97-98^{\circ}$ (corr.). The mixed melting-point with authentic pregnane-3( $\alpha$-ol-20-one acetate was $98-100^{\circ}$ (corr.).

\section{SUMMARY}

1. Pregnane-3( $\alpha)$-ol-20-one has been isolated from the products of hydrolysis ( $\mathrm{HCl}$ ) of 'sodium pregnanediol glucuronidate' prepared from human pregnancy urine.

2. 'Sodium pregnanediol glucuronidate' purified by precipitation from aqueous acetone with dry acetone and by crystallization from $90 \%(\mathrm{v} / \mathrm{v})$ aqueous ethanol, contains about $20 \%$ of a watersoluble derivative of pregnane-3( $\alpha)$-ol-20-one. This impurity cannot be removed by further 'purification' by the same methods.

3. It is suggested that the failure of several workers to obtain more than $70 \%$ of the theoretical yield of pregnanediol after acid hydrolysis of 'sodium pregnanediol glucuronidate' may be partly accounted for by these findings.

The work reported here is part of a programme of research undertaken at the request of the Scientific Committee on Human Fertility of the Medical Research Council. The authors are indebted to the Medical Research Council for a grant from which the expenses of the work were defrayed and for a personal grant to one of them (N.G.) They also wish to express their gratitude to Mrs G. F. Marrian for carrying out the microanalyses, to $\mathrm{Dr}$ W. F. T. Haultain, O.B.E., M.C., for arranging for supplies of urine from the Simpson Memorial Maternity Pavilion, Edinburgh Royal Infirmary, and to Dr I. D. E. Storey who assisted in the preparation of some of the 'sodium pregnanediol glucuronidate' used. 


\title{
REFERENCES
}

Astwood, E. B. \& Jones, G. E. S. (1941). J. biol. Chem. 137, 397.

Bloch, K. (1945). J. biol. Chem. 157, 661.

Callow, N. H., Callow, R. K. \& Emmens, C. W. (1938). Biochem. J. 32, 1312.

Marker, R. E. \& Kamm, O. (1937). J. Amer. Chem. Soc. 59, 1373.
Marker, R. E., Kamm, O. \& Wittle, E. L. (1937). J. Amer. Chem. Soc. 59, 1841.

Talbot, N. B., Berman, R. A., MacLachlan, E. A. \& Wolfe, J. K. (1941). J. clin. Endocrinol. 1, 668.

Venning, E. H. (1937). J. biol. Chem. 119, 473.

Venning, E. H. (1938). J. biol. Chem. 126, 595.

Venning, E. H., Hoffmann, M. M. \& Browne, J. S. L. (1942). J. biol. Chem. 146, 369.

\section{The Inhibition of Urease and Succinoxidase by Metabolic Products of $p$-Dimethylaminoazobenzene and by some Related Amines}

\author{
By L. A. ELSON and C. HOCH-LIGETI, The Chester Beatty Research Institute, \\ The Royal Cancer Hospital (Free), London, S.W. 3
}

(Received 17 December 1945)

The inhibition of activity of a cozymase enzyme system from yeast by metabolic products of the carcinogenic azo compound $p$-dimethylaminoazobenzene has been described by Kensler, Dexter \& Rhoads (1942). The metabolites isolated from the urine of rats treated with $p$-dimethylaminoazobenzene (Stevenson, Dobriner \& Rhoads, 1942) were $p$-aminophenol, $N$-acetyl- $p$-aminophenol, $p$ phenylenediamine, and $N: N^{\prime}$-diacetyl-p-phenylenediamine; and it was assumed that the azo linkage is split to give the primary metabolites aniline and $a s$-dimethyl-p-phenylenediamine from which the products isolated are subsequently formed.

Inhibition of the enzyme system was observed with $p$-phenylenediamine and with $a s$-dimethyl- $p$ phenylenediamine. A number of other aromatic diamines also were found to be inhibitory, and it was suggested that the inhibition is due to the oxidation products of the diamines. Attempts were made to correlate the carcinogenic action of the azo compounds with the stability of the free radical of their metabolic products. Inhibition of yeast carboxylase by these diamines was also found (Kensler, Young \& Rhoads, 1942).

Potter (1942) and Potter \& Dubois (1943) have extended this work to the succinoxidase system of rat liver and to urease, both of which are considered to require an intact - $\mathrm{SH}$ group for activity. Both enzymes are also strongly inhibited by the diamines, and the conclusion that the oxidation products are the actual inhibitors was confirmed. The fact that the activity of the succinoxidase system, in common with that of some other enzyme systems, is usually very low in tumour tissues has led to speculation that the mechanism of the production of cancer by chemical means may be connected with the inhibitory effects of metabolic products of carcinogens on such systems (cf. Potter, 1943, 1944).

As part of an investigation designed to obtain more concrete evidence for the basis of such theories of carcinogenic action we have investigated the behaviour of the succinoxidase system of rat livers towards the metabolites of $p$-dimethylaminoazobenzene during the period of feeding this liver carcinogen.

For this purpose it was first necessary to examine more fully the conditions of inhibition of liver succinoxidase by the known metabolites of $p$ dimethylaminoazobenzene, both in control animals which were fed on normal 'stock' diets and on diets similar to those of animals under treatment for tumour production except for the omission of the $p$-dimethylaminoazobenzene.

Sine it has been shown (Elson \& Warren, 1944) that benzidine can be isolated from the urine of rats receiving azobenzene, and it is probable that $p$-dimethylaminoazobenzene also undergoes the 'benzidine' rearrangement in vivo to give as the main product of this change 2:4'-diamino-5dimethylaminodiphenyl (I) (Jacobson \& Kunz, 1898), we have included in the investigation these and related compounds.

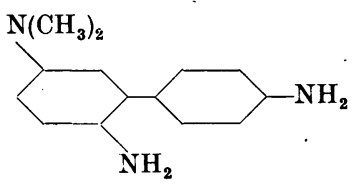

(I) 